\title{
THE ROLE OF PERSONALITY TRAITS, SELF-EFFICACY AND SITUATIONAL FACTORS IN SHAPING KNOWLEDGE ABSORPTION ACTIVITIES
}

\author{
Siti Nur Shahira Dahari ${ }^{1}$ and Siti Khairunnisa Sheikh Abdul Mutalib ${ }^{2}$ \\ ${ }^{1}$ Ms. Durham University, United Kingdom, dahari.s.shahira@durham.ac.uk \\ ${ }^{2}$ Ms., Northumbria University, United Kingdom, siti.mutalib@northumbria.ac.uk
}

\begin{abstract}
Today's, knowledge has turned into the most critical source and valuable assets to any institutions and organizations. Subsequently, this lead to the importance role of organization to sustain its competitiveness, numerous organizations and institutions at the present acknowledge the role of knowledge engagement in creating and maintaining a competitive advantage is essential in order to build up organization success. Knowledge comprises in creating competitive advantage and is influential in improving performance and outcomes. Organizations necessity, therefore, plays vital role in preserving employees knowledge and take appropriate actions to use successfully both tacit and explicit knowledge which is often significance to their operations and make it accessible to their employees. This conceptual paper attempts to develop a conceptual framework in relation to individual Personality traits, Self-efficacy and Situational factors components impacting the Knowledge Absorption activities on knowledge worker. This study can possibly provide theoretical understanding as it could add to our knowledge about relations and influences of the Personality traits, Self-efficacy and Situational factors with workplace Knowledge Absorption activities, with a particular concentrate on the Knowledge Worker, and their capacity in learning and ability to pertain and apply the knowledge according to organization context and resulting Knowledge Absorption productivity. In addition, this study shows conceptual progress on the issue of how broad personality characteristics such as the Big 5, Self-efficacy and Situational factors could have their effects on performance outcomes, by exploring potential predictors that consist of the elements of the Self-efficacy, Situational factors and Big Five Personality Traits (B5), i.e., conscientiousness, extraversion, agreeableness, openness, and neuroticism.
\end{abstract}

Keywords: Knowledge Worker, Big Five Model, Personality Traits, Self-Efficacy, Situational Factors, Knowledge Absorption.

\section{INTRODUCTION}

Knowledge is an intriguing dynamic human process (Nonaka and Takeuchi, 1995), as development of data, information, technology and innovative progression grows rapidly, the world today has become more knowledge based intensive. In addition to that, knowledge is not only data or information but as well as that its compelling use is dependent upon the ability of people collaborating with it (Malhotra, 2000). Numerous organizations now recognize the part of knowledge involvements in making and keeping up competitiveness in the business operations. (Drucker, 1993; Toffler, 1981). Knowledge builds competitive advantage and is 
influential in improving performance and knowledge workers productivity. Growing rivalry, relentless changes and mergers in industry have, regardless, made the threat of losing valuable knowledge, due to exchange employee's termination, turning into a main problem (Gunnlaugsdottir, 2003). Information and knowledge empowers an organization to settle on better choices and contend successfully (DeFillippi et al., 2006). Organizations necessity, therefore, plays vital role in preserving employee knowledge and take appropriate actions to use successfully both tacit and explicit knowledge which is often significance to their operations and make it unequivocally accessible to their workers. As knowledge worker has become essential elements in organizations performance and outcomes, hence this conceptual paper addresses this study by suggesting individual personality, self-efficacy and situational factors may influences knowledge absorption activities of knowledge workers in organizations.

Objectives of the study;

2. To examine whether Personality traits has a positive effects on Knowledge Absorption activities

3. To examine whether Self-efficacy has a positive effects on Knowledge Absorption activities

4. To examine whether Situational factors has a positive effects on Knowledge Absorption activities

5. To formulate a model of Knowledge Absorption activities among knowledge workers, with the specific consideration of personality differences, self-efficacy and situational factors variables.

\section{LITERATURE REVIEW}

\subsection{Knowledge Worker}

In this period of time, work in organization has turned out to be unpredictable and notably knowledge oriented (Eppler et al., 1999). The developing pattern towards Knowledge Workers in the working capacity is, without a doubt, are seen as essentials elements of the economy and society (Drucker, 1995; Lavoie et al., 2002; Overbeek, 2007). In previous studies by Mladkova, Zouharova, and Novy (2015), knowledge workers are considered as those taking after following qualities;

a) Individuals who are exceptionally dedicated to what they do; driven by achievement.

b) Creating, apply, and transmit knowledge; exists among professional level.

c) Play significant part of the system external and internal in the organizations.

d) A knowledge worker's position requires continuous learning, creativity, innovation and improvement, with tasks involves and critical thinking abilities.

e) Individuals who are exceptionally dedicated to what they do, work in an independent with leadership influence

f) Highly flexible and ability to adapt in any task given, and their key concentration is the improvement of their professions.

Davenport and Prusak (2000) in their studies describe Knowledge Workers as individual that create knowledge and make use of it as a main part of their aspect of work, which can be seen in professionals level. This idea was later extended by portraying Knowledge Workers as individuals with a high level of education background or expertise whose work includes the creation, appropriation, or utilization of learning and knowledge (Davenport, 2002). Subsequently, supported by Horvath (2011), describe the meaning of Knowledge Workers as any individual who works as a profession that very much use of, creating and application of knowledge.

Through the preceding definitions, Knowledge Workers aspect of work scope and responsibilities could be describe with the following activities: creation, acquisition, analyzing, storing, transmitting and transferring, critical thinking skills, problem solving, breaking down, programming, appropriating, and various different undertakings that require change of data, information, tacit and knowledge into explicit product. By this more extensive definition, example of Knowledge Workers may comprise of professional profession as the followings; academics, lawyers, financial analysts, manager and others.

\subsection{Knowledge Absorption Activities}

Knowledge Absorption incorporate the learning process from experience, which encompass relational interpersonal; communication between employees which prompt the Knowledge Absorption (Kayes, Kayes, \& Yamazaki, 2005). Furthermore, Knowledge Absorption in the organizations depends on the capacity of its individual individuals to gain as a matter of fact and to apply this knowledge and able to apply into the 
systems. Supported by Cohen and Levinthal, (1990), in their study recognized that the capacity to learn and absorb knowledge from experience and be able to apply into the organizations operations capacity rests on the individual abilities.

In prior literature (Lindsay and Norman, 1977) from the viewpoint of information processing knowledge absorption has been regards of individual learning. Due to that perception, learning as an objective process where prior knowledge structures grow to be correspond to subsequent cognitive representations. Compelling Knowledge Absorption rests in the capacity of people to create, accumulate, arrange and apply new knowledge. These capacities, or skills, result from a individual's capacity to create connections and interpret thoughts across limitation.

Powerful Knowledge Absorption over diversity of ethnic societies and nationality turns out become significant part of organization advancement and accomplishment as organizational and institutions desire to reach globally. Moreover, consistent with Knowledge Absorption approaches by Cohen and Levinthal (1990), define that Knowledge Absorption is a development of learning from prior experience. Thus, in this study author conclude that's Knowledge Absorption as a process of individual learning encompasses through each of these stages of recognizing, acquiring and applying, ability to apply knowledge accordance to organizations needs and context.

\subsection{Personality Traits}

According to Srivastava (2015), the Big Five are essentially is a trait in a group; categorization of personality traits, in particular, a synchronize arrangement that place together all traits which can describe individuals personality. Agnieszka (2013) define personality is outlined as a set of traits, and on the contrary it can be the root of stability of behavior, additional on the consistency individual's behavior; the greater the potency of a specific feature throughout individuals, the much more likely it can be that they would display a clear behavior. More directly personality traits are defined in terms of generalized scope within an individual dissimilarity or contrasts in their tendency to demonstrate habits regarding emotions, thoughts and also actions (McCrae \&Costa, 1990).

In the current study, the author adopts the personality traits from Goldberg's (1990) Big Five Model (Big 5) as independent variables used to predict Knowledge Absorption activities. More specifically, in this research model, an individual's traits are captured by the dimensions of openness, neuroticism, extraversion, agreeableness and conscientiousness is proposed to influence knowledge workers absorption tendencies. Furthermore, as in line in looking at individual performance and outcomes, the Big Five has frequently been used to forecast job performance (Shaffer \& Postlethwaite, 2012) and also academic performance (Poropat, 2009).

The next several paragraphs briefly define each of the five personality traits, and develop a rationale for how they are expected to relate to academic Knowledge Absorption activities in the current study. Individual with high Openness reflects the degree which a person participates and engaging in creativity, positive thinking and also curiosity.

In contrary, Individual with Neuroticism trait portrays individual typically experience unfavourable moods, in addition to seems unpleasant thoughts effortlessly, like anger, anxiousness, or maybe worried tension. Individual with Extraversion traits is defined as the degree of individual who are passionate, active, like to be sociable, talkative and energetic. Individual with Agreeableness personality shows high trustworthiness as well as corporative with one and another. Lastly, Individual with Conscientiousness would be the degree of individual that are usually diligent, independent and very well planned person.

\subsection{Self-efficacy}

The historic root of the theory of self-efficacy was introduced by Bandura in 1977. The idea of self-efficacy is described as the judgments of people in regards to their abilities to classify and implement tasks required to accomplish particular intensity of performance (Bandura, 1986). Concisely, self-efficacy is defined as capability refers to individual beliefs about their capacity to effectively accomplish objectives and oversee situations that influence their lives and performance and ability to learn or perform behaviors at assigned levels (Bandura, 1989, 1986, 1997).

Wasko and Faraj, (2005), noted that self-efficacy can influence and encourage workers to bring new ideas from the outside into the organization. This is supported by Pajares (1997), across diverse studies fields, self-efficacy have been shown and found to be related in a variety of contexts especially in behavioral and performance. According to Bandura (1997), and individuals with low self-efficacy are commonly associated with sorrow, uneasiness, and vulnerability. 
In contrary, individuals who have a high self-efficacy tend to view themselves successful situation, therefore are likely to be positive which drive strength for their performance (Schwarzer et al., 2000). Thereby, individuals with high self-efficacy have a tendency overcome their obstacles ad challenges and regard this circumstance as a test as opposed to a restraint. Therefore, for purposes of this conceptual paper address self-efficacy by referring to individuals' beliefs regarding their capability successfully in absorbing skills and knowledge and able to bring new knowledge and apply the knowledge into the organization operation and practice.

\subsection{Situational factors}

Looking into situational factors, whereas environmental context would be the key elements to manipulate or increase knowledge workers involvement in Knowledge Absorption Activities. In perspective of the early disillusionments in anticipating behavior from personality traits (e.g., Allport \& Vernon, 1933; Dudycha, 1936; Hartshorne \& May, 1928; Newcomb, 1929), according to Mischel (1968) even though a few expectations could be produced using individual characteristics, the most capable ones would likely be made by considering situational variables into situation. In this study, the situational factors have been identified drawn by prevalent studies as situational level factors that might associated with knowledge absorption activities among knowledge worker, relevant factors been proposed include such things as:

(a) Administrative duties;

(b) Information Technology Infrastructure;

(c) Employee position,

(d) Years of services at organization,

(e) Funding and other similar individual level variables may also be relevant and will be measured.

\section{THEORETICAL FRAMEWORK}

This conceptual paper proposes that the personality traits, self-efficacy and situational factors are necessary factors to consider when explaining knowledge worker Knowledge Absorption activity. It has been suggested that the Big Five is the prominent and comprehensive model for capturing personality traits (Costa \& McCrae, 1992). It is extensively recognized that the Big Five traits such as neuroticism, extraversion, openness, agreeableness, and conscientiousness detained most of the individual dissimilarities in behavioural patterns (Costa \& McCrae, 1992).

Moreover, Self-efficacy beliefs have likewise gotten expanding consideration in education and learning process. More study demonstrates that self-efficacy give impacts on motivation, learning, and achievement (Pajares, 1996; Schunk, 1995). In addition to that, Mischel (1968) recommended that although some predictions could be made from personality traits, the most effective ones would likely be made by considering situational factors into account and therefore is an appropriate theoretical framework for studying individual disparities and performance in a wide range of domains. The theoretical model in Figure 1 summarizes the key variables of proposed study.

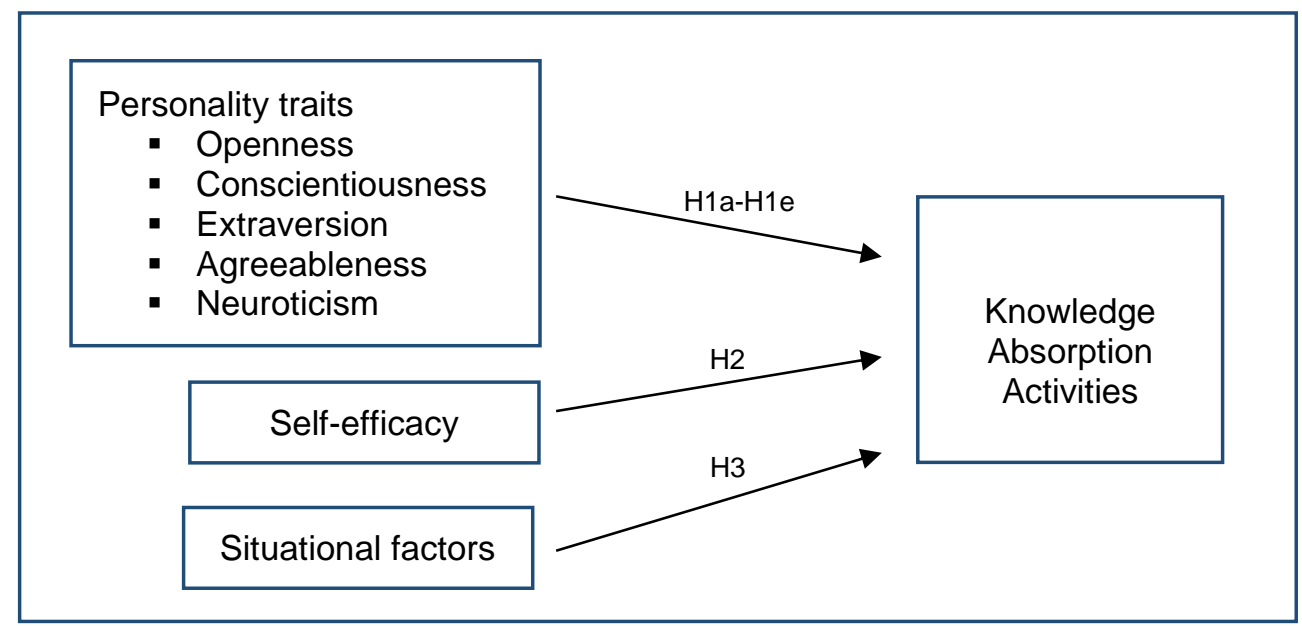

Figure 1: Conceptual Overview of a Model of Knowledge Absorption Activities

The framework above represents the potential conceptual framework. The research objective was to examine the individual factors influencing the Knowledge Knowledge Absorption Activities among 
academics. Hence the independent variables for the study consisted of five variables of Big Five model, Selfefficacy and Situational factors as predictors and Knowledge Absorption Activities as dependent variable. This study has formulated hypotheses which proposed the relationship of the Personality Traits, Self-efficacy and Situational factors variables with Knowledge Absorption activities, more specifically:

H1a. Openness has a positive effect on Knowledge Absorption Activities

H1b. Conscientiousness has a positive effect on Knowledge Absorption Activities

H1c. Extraversion has a positive effect on Knowledge Absorption Activities

H1d. Agreeableness has a positive effect on Knowledge Absorption Activities

H1e. Neuroticism has a negative effect on Knowledge Absorption Activities

H2. Self-efficacy has a positive effect on Knowledge Absorption Activities

H3. Situational factors have a positive effect on Knowledge Absorption Activities

\section{DATA ANALYSIS METHODS}

This study proposed that data collected for this study will be explored using descriptive (that include frequencies, mean, median and mod). Reliability test will be carried out to test the consistency of the respective scales. SPSS v. 20 will be used to examine predictor variables. Statistical technique (Multivariate Data Analysis) will be used to analyze data that comprise more than one variable and inferential statistical analysis (i.e., correlation, regression and factor analysis) data will also be assessed to ensure that are met so that they can be used to test hypotheses.

\section{CONCLUSION AND FUTURE STUDIES}

The outcome from this study is predicted to improve understanding and support Knowledge Worker as organization asset with the development of another new model for Knowledge Absorption activities resulting from Personality traits, Self-efficacy and Situational factors perspective. Thereby, this study expected it can potentially help institution and organization to better understand how they might increase their Knowledge Worker success and involvement in Knowledge Absorption Activities. In addition, this study also proposes future studies by looking deeper upon other theory such as other Social Cognitive Theory Bandura (1988) for further research. Therefore, It is hope that this study can aid insight to other researchers and subsequently contributes to the body of literature with specific focus on Personality traits, Self-efficacy, Situational factors and Knowledge Absorption literature.

\section{REFERENCE LIST}

Agnieszka, T. K. (2013). Big Five Personality Traits Model in Electoral Behaviour Studies. Romanian Journal of Political Science, 13 (2), 69.

Allport, G.W., \& Odbert, H.S. (1937). Trait-names: A psycho-lexical study. Psychological Monographs, 47 (Whole No. 211).

Bandura, A. (1986) Social Foundations of Thought and Action: A Social Cognitive Theory (Englewood Cliffs, $\mathrm{NJ}$ : Prentice-Hall)

Bandura, A. (1988). Self-efficacy conception of anxiety. Anxiety Research, 1, 77-98.

Bandura, A. (1989). Human agency in social cognitive theory. American Psychologist, 44, 1175-1184.

Bandura, A. (1997) Self-efficacy: The Exercise of Control (New York: Freeman)

Bandura. A. (1977) Self-efficacy: Toward a Unifying Theory of Behavioural Change. Psychological Review, $84,191-215$

Cohen, W. M., Levinthal, D., \& Reginald H. Jones Center for Management Policy, Strategy, and Organization. (1990). Absorptive capacity: A new perspective on learning and innovation. Philadelphia, PA: Reginald H. Jones Center, Wharton School, University of Pennsylvania.

Costa, P.T., Jr., McCrae, R.R. (1992). Revised NEO Personality Inventory (NEO-PI-R) and NEO Five-Factor 
Inventory (NEO-FFI) manual. Odessa, FL: Psychological Assessment Resources.

Davenport, T. H., \& Prusak, L. (2000). Working knowledge: How organizations manage what they know. Boston, Mass: Harvard Business School Press.Davenport, 2002).

DeFillippi, R. J., Arthur, M. B. \& Lindsay, V. J. (2006). Knowledge at Work. Oxford: Blackwell Publishing.

Drucker, P. F. (1995). People and performance: The best of Peter Drucker on management. Oxford: Butterwoth Heinemann.

Dudycha, G.J. 1936: An objective study of punctuality in relation to personality and achievement. Archives of Psychology, 29, No. 204, 1-53.

Eppler, M., Röpnack A., Seifried P. (1999). Improving Knowledge Intensive Processes through an Enterprise Knowledge Medium. Prasad, J. (Ed.): Proceedings of the 1999 ACM SIGCPR Conference 'Managing Organisational Knowledge for Strategic Advantage: The Key Role of Information Technology and Personnel', 222-230

Goldberg, L. R. (1990). An alternative "Description of personality": The Big-Five factor structure. Journal of Personality and Social Psychology, 59, 1216-1229.

Gunnlaugsdottir, J. (2003) Seek And You Will Find, Share And You Will Benefit: Organising Knowledge Using Groupware Systems, International Journal of Information Management, Volume 23, Issue 5, pp. 363-380.

Hartshorne H, May MS. Studies in the nature of character: Studies in deceit. New York: Macmillan; 1928.

Horvath, A., Del Re, A. C., Flückiger, C., \& Symonds, D. (2011). The alliance. In J. C. Norcross (Ed.). Relationships that work (pp. 25-69). New York, NY: Oxford University Press. Kayes, Kayes, \& Yamazaki, 2005

Lavoie, M., Roy, R., \& Therrien, P. (2003). A growing trend toward knowledge work in Canada. Research Policy, 32(5), 827-844.

Lindsay, P. H., \& Norman, D. A. (1977). Human information processing: An introduction to psychology. New York: Academic Press.

McCrae, R. R., \& Costa, P. T. (1990). Personality in adulthood. New York: The Guilford Press.

McCrae, R. R., \& Costa, P. T. (2006). Personality in adulthood: A five-factor theory perspective. New York, NY [u.a.: Guilford Press.

Mischel, W. (1968). Personality and assessment. New York: Wiley

Mladkova L, Zouharova J, Novy J. Motivation and knowledge workers. Social and Behavioral Sciences Procedia. 2015; 207:768-76. DOI:10.1016/j.sbsproNewcomb, 1929)

Newcomb, T. M. Consistency of certain extrovert-introvert behavior patterns in 51 problem boys. New York: Columbia University, Teachers College, Bureau of Publications, 1929

Overbeek, S.J. (2007), Improving efficiency and effectiveness of knowledge exchange between knowledge workers, Journal of Knowledge Management, 5(1), 24-38

Pajares F. (1997) Current Directions in Self-efficacy Research. In: M. Maehr \& P. R. Pintrich (Eds.). Advances in Motivation and Achievement: Volume 10 (Greenwich, CT: JAI Press); 1-49

Poropat, A. E. (2009). A meta-analysis of the Five-Factor Model of personality and academic performance. Psychological Bulletin, 135, 322-338. doi:10.1037/a0014996

Rogers, D. L. (2000). A Paradigm Shift: Technology integration for higher education in the new millennium. Educational Technology Review, 6(3), 19 - 27.

Sanjay Srivastava, John Flournoy, \& Gerard Saucier. (2015). A Network Approach to Characterizing Personality in the Life and Time Longitudinal Sample. Figshare.

Schunk, D. H. (1994) Self-regulation of Self-efficacy and Attributions in Academic Settings. In D. H. Schunk \& B. J. Zimmerman (Eds.), Self-regulation of Learning and Performance: Issues and Educational Implications (Hillsdale, NJ: Erlbaum); 75-99.

Schwarzer, R., Schmitz, G.S., \& Tang, C. (2000). Teacher burnout in Hong Kong and Germany: A crosscultural validation of the Maslach Burnout Inventory. Anxiety, Stress, and Coping, 13, 309-326. 
Shaffer, J. A., \& Postlethwaite, B. E. (January 01, 2012). A Matter Of Context: A Meta-Analytic Investigation Of The Relative Validity Of Contextualized And Noncontextualized Personality Measures. Personnel Psychology, 65, 3, 445-493.

Wasko, M.M. and S. Faraj. Why should I share? Examining knowledge contribution in electronic networks of practice. MIS Quarterly 29, 1 (2005), 1-23. 